\title{
Development of a vertical semi-active suspension system using variable hydraulic dampers
}

\author{
Y. Sugahara ${ }^{1}$, T. Kojima ${ }^{1}$, Y. Akami ${ }^{2} \&$ Y. Igarashi ${ }^{2}$ \\ ${ }^{1}$ Railway Technical Research Institute, Japan \\ ${ }^{2}$ Hitachi Automotive Systems, Ltd, Japan
}

\begin{abstract}
Plans are being made in Japan to launch luxury cruise trains for sightseeing tours. These trains are expected to use both main and secondary railway lines on the network. Secondary lines in particular can sometimes be subject to significant irregularities because maintenance criteria are lower than for mainlines. As a result, rigid-body-mode vibrations, and in particular those in the $1-2 \mathrm{~Hz}$ frequency range, tend to increase, which may result in reduced ride comfort. As such, a secondary suspension damping control system using variable vertical hydraulic dampers was developed to mitigate this type of vibration. The system consists of four dampers, a controller, and four accelerometers. Variable vertical dampers are mounted parallel to the secondary air springs. The damping force can be controlled by the command current. The control algorithm which controls the variable dampers is based on the sky-hook control theory. The controller is also equipped with an algorithm which is geared to monitor the state of the damper, which does not require the use of sensors in the system. The algorithm examines the phase difference between the bounce and pitch vibration modes of the car body with the accelerometers used to control the dampers. When a fault is detected, a fail-safe function is activated, stopping damper controlling automatically. Vehicle running tests using an actual vehicle equipped with the control system were carried out. In the tests, the system reduced the peak in the power spectrum density for vertical vibration acceleration due to the rigid-body-mode vibration of the car body by almost 40 per cent compared to when the system was not used.

Keywords: railway vehicle, semi-active suspension, vibration control, secondary suspension, variable damper.
\end{abstract}




\section{Introduction}

Plans to launch new luxury rail tours, called "Cruise trains" have recently emerged in Japan [1]. Designed to carry passengers around tourist spots throughout Japan, these trains will run on both main lines and secondary lines. Given that track maintenance criteria on secondary lines are not as high as for mainline, they tend to suffer from a relatively higher degree of track irregularity than main lines. As a result, $1-2 \mathrm{~Hz}$ rigid-body-mode vibrations increase, which in turn has led to concerns about the associated impact on ride comfort. Maintenance criteria of secondary railway lines are determined according to volume and speed of traffic using the route. Raising these criteria simply to cater for high-end luxury vehicles would be difficult, given the cost and other constraints of such a measure. Consequently, there was a strong desire to reduce this vibration problem using an on-board solution.

Active (or semi-active) suspension is known to be effective for reducing this type of car body vibration, and research and tests have already been carried out in this field $[2,3]$. The authors of this paper developed a secondary suspension vibration control system with variable vertical hydraulic dampers. This system was then successfully adapted to an actual sightseeing limited express train which has coil springs in the secondary suspension [4]. Subsequently, this system has been advanced so that the system can be applied to more recent vehicles which have air springs in the secondary suspension; the variable damper was improved in terms of responsiveness, and the bending vibration of the car body can be controlled simultaneously along with rigid-body-mode vibrations, etc.

This paper describes the overall structure of the advanced system and the vehicle running test results using an actual vehicle. The results demonstrated that this system is effective in reducing vertical bending mode vibrations of the car body as well as rigid-body-mode vibrations.

\section{Structure of the vertical semi-active suspension system}

\subsection{Basic architecture}

Figure 1 shows the overall structure of the secondary suspension damping control system which was developed. Variable vertical dampers, used for damping control, are mounted parallel to the secondary (air) springs. Each car is equipped with four dampers, a controller, and four accelerometers.

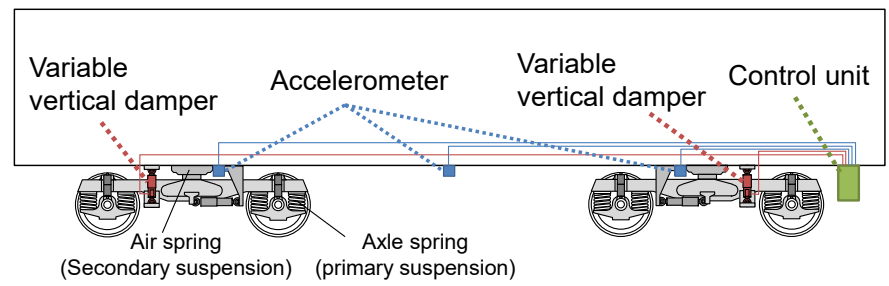

Figure 1: Secondary suspension damping control system. 
The controller calculates the desired damping force required to suppress the vertical vibration acceleration of the car body obtained from accelerometers, and supplies a command current to the dampers. The controller is also equipped with functions for detecting abnormalities in the system.

\subsection{Variable vertical damper}

Figure 2(a) shows variable vertical dampers designed for bolsterless bogies equipped with air springs.

The basic specifications of these variable dampers are, damper installation length of $450 \mathrm{~mm}$, maximum damping force of $11.8 \mathrm{kN}$ (for a piston speed of $0.5 \mathrm{~m} / \mathrm{s}$ ), and damping force on each damper can be adjusted by means of two control valves.

The damping characteristics observed for the command current are illustrated in Fig. 2(b). Damping force was at its lowest with a command current of approximately $0.3 \mathrm{~A}$, and at its highest with a current of $1.5 \mathrm{~A}$.

The joints which fix the damper to the car body and the bogie frame use spherical bearings to permit mounting of the dampers on bolsterless bogies. This allows the bogies and car body to move together smoothly, in the lateral direction and in the longitudinal direction when the bogies are turning.

When no power is being supplied to the control valves, these dampers operate as passive dampers with a damping coefficient of $30 \mathrm{kN} /(\mathrm{m} / \mathrm{s})$, which is appropriate for ride comfort, and confirms that the fail-safe function is achieved.

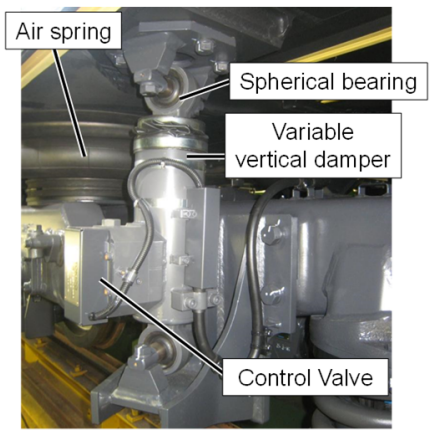

(a) Appearance

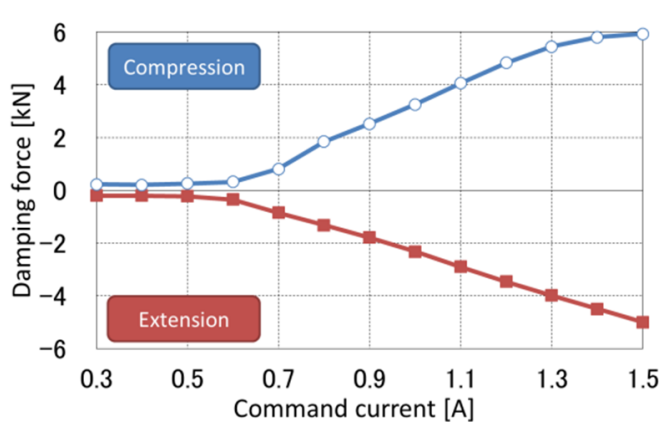

(b) Damping force characteristics

Figure 2: Variable vertical damper.

\subsection{Accelerometers}

Accelerometers for detecting vertical vibration were installed under the floorboard of each car as shown in Fig. 3(a). In many cases, four accelerometers are used, although the number and placement of accelerometers to be mounted on the car body ultimately depends on the number and shape of the car body vibration modes to be controlled. For example, in the case of controlling bouncing, pitching, rolling 
and bending modes of the car body vibrations, accelerometers were installed according to the diagram in Fig. 3(b).

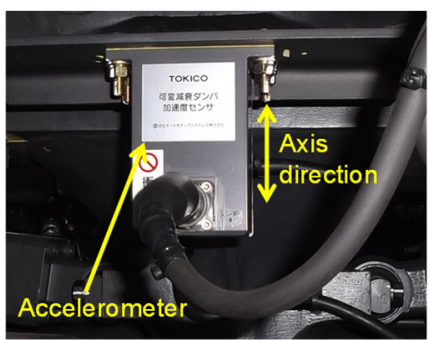

(a) Appearance

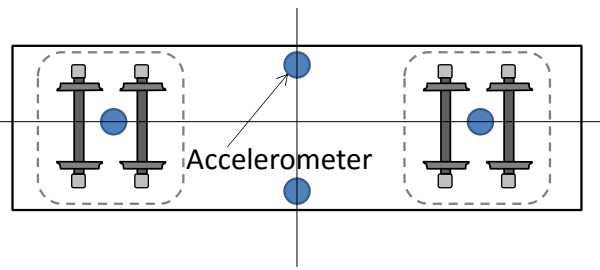

(b) An example of accelerometers placement

Figure 3: Accelerometer for control.

\subsection{Control algorithm}

The sky-hook control law [5] was adopted for controlling the dampers (as shown in Fig. 4). The vertical vibration acceleration of the car body is separated into bouncing, pitching, rolling and bending modes, and each component is integrated through a filter to obtain the vibration velocity for each vibration mode. The skyhook force (desired damping force) for each vibration mode is calculated by multiplying its vibration velocity by the sky-hook gain, and is sent to the variable vertical dampers as a command current to control the damping force. The skyhook gains are determined by vehicle running tests on a commercial line.



Figure 4: Block diagram for damping control.

\subsection{Fault detection algorithm for vertical damper}

In addition to the above mentioned functions necessary for controlling the dampers, the controller is also equipped with functions to detect faults such as breaking of 
wires, accelerometer faults and damper faults. For damper fault detection in particular, a newly developed method is adopted.

Monitoring the working condition of dampers is easy if damping force can be measured using a sensor mounted directly on the damper. However, for practical reasons, it is preferable to avoid having special sensors on the dampers just for fault detection. The developed method makes it possible to monitor the working condition of the damper using the accelerometers installed for vibration control. Figure 5 shows the algorithm [6]. The algorithm separates vertical vibration acceleration of the car body into bounce and pitch vibration modes, then calculates the phase difference between them. If the phase difference deviates from a predetermined range, a damper fault is detected.

When a fault is detected, vibration control is automatically stopped and the type of fault is indicated by a seven-segment display installed in the controller. Events occurring inside the controller are recorded. This record is stored and used for future maintenance.

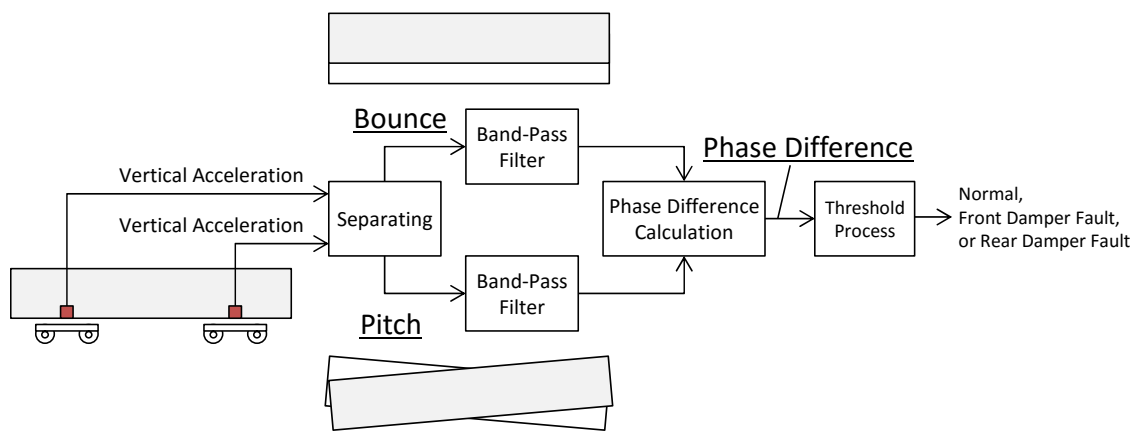

Figure 5: Block diagram for fault detection for vertical dampers.

\section{Performance demonstration of the system using actual vehicles in running tests}

\subsection{Test condition}

Vehicle running tests were carried out in cooperation with the Kyushu Railway Company. As track maintenance criteria in the running test section were not so high, there was a tendency for $1-2 \mathrm{~Hz}$ car body vibrations in rigid-body-modes to increase. The test vehicle, which was a meter-gauged car, had a car length of $20 \mathrm{~m}$ and a distance between bogie centres of $14.15 \mathrm{~m}$. With the aim of maximizing the damping-control performance of the variable vertical dampers, the orifices were removed from the air springs of the test vehicle so that the dampers were almost entirely responsible for the damping of the secondary suspension system. A conventional vehicle which had a similar bogie structure to that of the test vehicle, was also made to run along the same section and at the same speed, and the vibration accelerations of these vehicles were compared. 


\subsection{Test for vibration reduction}

The trial in which bouncing, pitching, and rolling mode vibration were controlled was called "Control A," and the trial when bending vibration was also controlled was called "Control B".

Figures 6 and 7 show the power spectral density (PSD) of the vertical vibration acceleration for the test section on the secondary line used in the tests (running speed of $60 \mathrm{~km} / \mathrm{h}$ ) where rigid-body-mode vibration of the car body was particularly marked. An acceleration PSD peak due to rigid-body-mode vibration was observed at approximately $1.4 \mathrm{~Hz}$ both directly above the rear bogie centre (Fig. 6) and at the centre of the car body (Fig. 7).

The vertical damper of the test car without control was designed to generate slightly larger damping force than the orifice in the air spring of the conventional car. It is for this reason that the vibration with a frequency around $1.4 \mathrm{~Hz}$ of the test car even without control was lower than that of the conventional car (Figs 6 and 7).

Applying "Control A", vibration with a frequency of $2 \mathrm{~Hz}$ or lower was generally suppressed as compared with the "Conventional car" case or "Test car without control" case, and the PSD peak at $1.6 \mathrm{~Hz}$ above the rear bogie centre was markedly reduced by approximately $90 \%$ compared with the "Conventional car" (Fig.6).



Figure 6: Vertical acceleration PSD of the car body floor above the rear bogie centre in the vehicle running test (running speed $=60 \mathrm{~km} / \mathrm{h}$ ).

Applying "Control A", rigid-body-mode vibration was suppressed; however, the PSD peak with a frequency of approximately $11 \mathrm{~Hz}$ due to the bending vibration at the centre of the car body increased instead. In contrast, applying "control B", in which the bending vibration of the car body is controlled in addition to the rigid-body-mode vibration, the PSD peak was reduced without adversely affecting the performance of 1-2 $\mathrm{Hz}$ rigid-body-mode vibration suppression (Fig. 7). 




Figure 7: Vertical acceleration PSD at the floor of car body centre in the vehicle running test (running speed $=60 \mathrm{~km} / \mathrm{h}$ ).

\subsection{Test for fault detection in vertical damper}

The vehicle ran in each of the following three modes: normal mode; fault mode in which one of two dampers on the front bogie was made faulty; and another fault mode in which one of two dampers on the rear bogie was made faulty.

The results are shown in Figure 8. The phase difference in the normal mode stayed roughly flat, whereas in the front damper fault mode it increased and in the rear damper fault mode it declined. Both fault modes were detected after the phase difference deviated from the normal range. The direction of the deviation indicates the location of the faulty damper (front or rear).

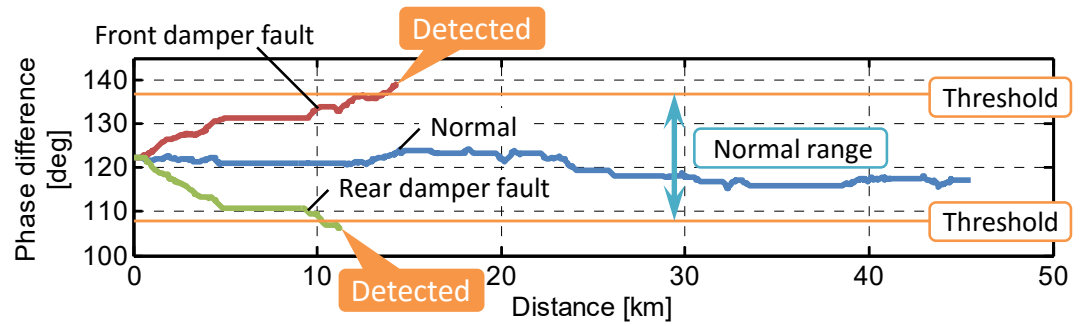

Figure 8: Result of damper fault detection test. 


\section{Conclusion}

This paper describes a control system for suppressing vertical vibration, namely rigid-body-mode vibration, of a car body, by controlling the damping force of variable vertical dampers mounted parallel to the air springs, with the aim of improving the ride comfort of vehicles. The vehicle running tests show that the system can reduce vertical bending mode vibrations as well as rigid-body-mode vibrations. The system can therefore be used to improve the ride comfort of certain trains at a reasonably low cost without having to change the track maintenance criteria.

All coaches of the cruise train "seven stars in Kyushu" provided by the Kyushu railway company in October 2013 [1], were equipped with the system, shown in Fig. 9. The system has contributed to improved ride comfort, and is scheduled to be adopted for some other trains in Japan.

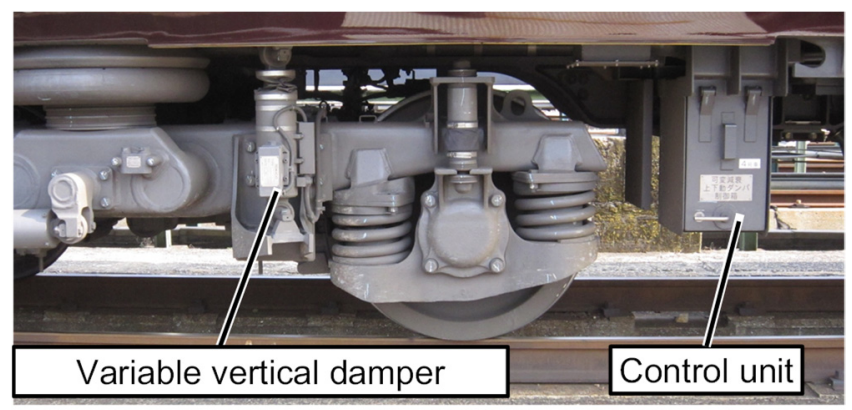

Figure 9: Installation of variable vertical damper and control unit (77 series coaches/Kyushu railway company).

\section{Acknowledgements}

Particular thanks are expressed to the relevant personnel at the Kyushu Railway Company, who provided valuable assistance and made it possible to carry out the vehicle running tests.

\section{References}

[1] H. Yanagawa, Towards Starting Operations of the Cruise Train "Seven Stars in Kyushu”. Japanese Railway Engineering, 53(4), pp. 19-21, 2013.

[2] S. Bruni, R. Goodall, T. X. Mei, and H. Tsunashima, Control and monitoring for railway vehicle dynamics. Vehicle System Dynamics, 45(7-8), pp. 743779, 2007.

[3] A. Stribersky, H. Muller, and B. Rath, The development of an integrated suspension control technology for passenger trains, Proceedings of the Institution of Mechanical Engineers, Part F: Journal of Rail and Rapid Transit, 212(1), pp. 33-42, 1998. 
[4] Y. Sugahara, T. Kojima, T. Morimitsu, S. Matsunaga, Y. Igarashi, and Y. Akami, Practical Use of a Vehicle Vibration Control System using Secondary Variable Vertical Dampers on a Sightseeing Train. Proceedings of the First International Conference on Railway Technology: Research, Development and Maintenance. Paper No. 31, 2012.

[5] D. Karnopp, M. J. Crosby, and R. A. Harwood, Vibration control using semiactive force generators. Transactions of the American Society of Mechanical Engineers, Journal of Engineering for Industry, Series. B, 96(2), pp. 619-626, 1974.

[6] T. Kojima, and Y. Sugahara, Fault Detection of Vertical Dampers of Railway Vehicle Based on Phase Difference of Vibrations. Quarterly Report of RTRI, 54(3), pp. 139-144, 2013. 